\title{
Determination of pyridoxal-5'-phosphate (PLP)-bonding sites in proteins: a peptide mass fingerprinting approach based on diagnostic tandem mass spectral features of PLP-modified peptides
}

\author{
Eric S. Simon ${ }^{1 *}$ and John Allison ${ }^{2}$ \\ ${ }^{1}$ Department of Biological Chemistry, University of Michigan, Ann Arbor, MI 48109, USA \\ ${ }^{2}$ Department of Chemistry, The College of New Jersey, Ewing, NJ 08628, USA \\ Received 7 May 2009; Revised 13 July 2009; Accepted 27 August 2009
}

\begin{abstract}
Peptides modified by pyridoxal-5'-phosphate (PLP), linked to a lysine residue via reductive amination, exhibit distinct spectral characteristics in the collision-induced dissociation (CID) tandem mass (MS/MS) spectra that are described here. The MS/MS spectra typically display two dominant peaks whose $\mathrm{m} / z$ values correspond to neutral losses of $\left[\mathrm{H}_{3} \mathrm{PO}_{4}\right](-98 \mathrm{Da})$ and the PLP moiety as $\left[\mathrm{C}_{8} \mathrm{H}_{10} \mathrm{NO}_{5} \mathrm{P}\right](-231 \mathrm{Da})$ from the precursor peptide ion, respectively. Few other peaks are observed. Recognition of this distinct fragmentation behavior is imperative since determining sequences and sites of modifications relies on the formation of amide backbone cleavage products for subsequent interpretation via proteome database searching. Additionally, PLP-modified peptides exhibit suppressed precursor ionization efficiency which diminishes their detection in complex mixtures. Presented here is a protocol which describes an enrichment strategy for PLP-modified peptides combined with neutral loss screening and peptide mass fingerprinting to map the PLP-bonding site in a known PLP-dependent protein. This approach represents an efficient alternative to site-directed mutagenesis which has been the traditional method used for PLP-bonding site localization in proteins. Copyright (C) 2009 John Wiley \& Sons, Ltd.
\end{abstract}

We present here a mass spectrometry (MS)-based method for determining the active-site lysine bonding residue to pyridoxal-5'-phosphate (PLP) in PLP-dependent enzymes. PLP is a unique post-translational modification (PTM) involved in catalyzing an assortment of reactions including decarboxylation, amino group transfers, and isomerization of amino acids. ${ }^{1,2}$ PLP-bonding sites have traditionally been determined using site-directed mutagenesis combined with spectroscopy and activity assays. ${ }^{3,4}$ The application of MS was considered here as an alternative to the laborious and time-consuming mutagenic approach due to the demonstrated success of MS for mapping other post-translational modifications (PTMs) in proteins. ${ }^{5}$ Tandem mass spectrometry (MS/MS) combined with proteome sequence databases and database search tools such as Mascot ${ }^{6}$ have allowed for the high-throughput analysis of large MS/MS spectral datasets for the interpretation of peptide sequences and PTMs. ${ }^{7}$ When combined with multiple fractionation techniques like cation exchange and reversed-phase liquid chromatography (RP-LC), which are commonly employed in bottom-up proteomic protocols, thousands of peptides can

*Correspondence to: E. S. Simon, Department of Biological Chemistry, University of Michigan, 300 N. Ingalls St., Ann Arbor, MI 48109, USA.

E-mail: essimon@umich.edu be analyzed leading to the identification of hundreds or thousands of proteins. $^{8}$ However, database search tools rely on backbone fragmentation for sequence interpretation. Some labile modifications on peptides can be unaccommodating to this approach as fragmentation often results in the selective, facile cleavage of the modification from the peptide ion. Phosphopeptides, for example, preferably release neutral $\left[\mathrm{H}_{3} \mathrm{PO}_{4}\right]$ from the side chain of a residue concomitant with a lack of backbone fragmentation. ${ }^{9,10}$ The resulting MS/ MS spectrum is often devoid of peaks that can be used to elucidate sequence information. Reported here is another such case where we have observed a selective, yet distinctive fragmentation pattern of peptides reductively aminated at lysine residues by PLP when analyzed via collision-induced dissociation (CID) tandem mass spectrometry. MS/MS spectra of PLP-modified peptides exhibit two dominant peaks representing product ions corresponding to neutral losses of $\left[\mathrm{H}_{3} \mathrm{PO}_{4}\right]$ and $\left[\mathrm{C}_{8} \mathrm{H}_{10} \mathrm{NO}_{5} \mathrm{P}\right]$ (representing the PLP moiety itself), respectively. Few other peaks are observed.

In addition to the low yield of sequence ion peaks generated from PLP-modified peptides in MS/MS spectra, there are other challenges to address when applying MS for bonding site localization. Among these challenges is the covalent Schiff base that is formed between PLP and proteins. $^{2,11}$ Since it is reversible, ${ }^{12,13}$ the Schiff base must be converted into a stable secondary amine via reduction 


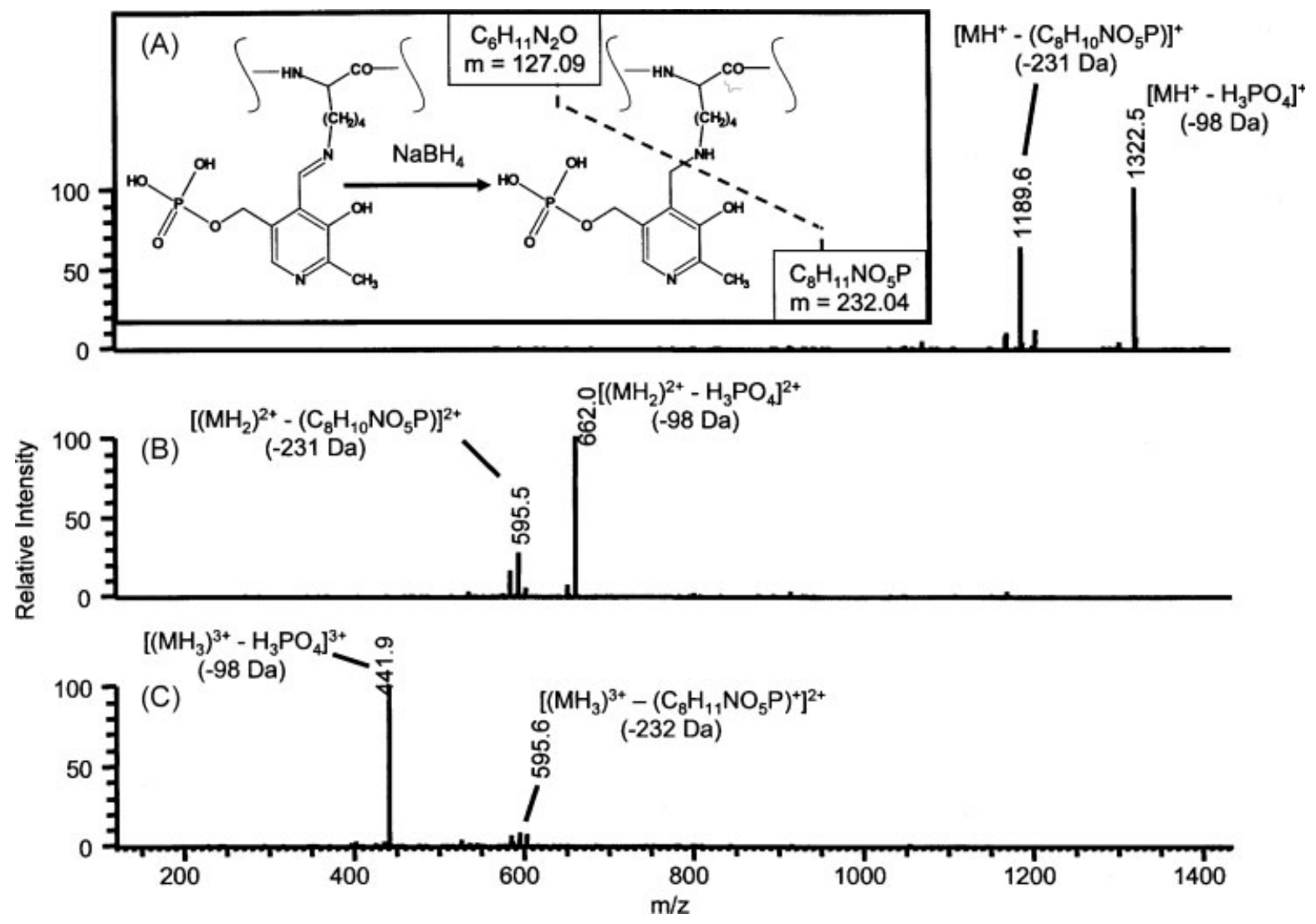

Figure 1. ESI-MS/MS spectra of $(A)$ singly, $(B)$ doubly, and $(C)$ triply charged precursor ions of a PLP-modified peptide with the amino acid sequence HHLGGAKQAGDV. Inset: $\mathrm{NaBH}_{4}$ reduction of the Schiff base of a PLPmodified lysine residue.

with sodium borohydride, $\mathrm{NaBH}_{4}$ (inset Fig. 1), to prevent dissociation during sample preparation. ${ }^{14,15}$ Stabilization is not a normal consideration for other PTMs like methylation ${ }^{16}$ and phosphorylation ${ }^{17}$ whose covalent attachments remain stable during protein denaturation and digestion. Another challenge, evident from our study here, is that PLP-modified peptides exhibit reduced detection efficiency relative to unmodified peptides. This is not surprising since phosphopeptides exhibit similar behavior. ${ }^{18}$ As a result, an enrichment strategy for PLP-modified peptides may be necessary to detect them in complex mixtures.

We report here a method for assigning PLP-bonding sites in proteins by combining the recognition of a distinct fragmentation pattern of peptides modified by PLP (at lysine residues via reductive amination) with peptide mass fingerprinting. ${ }^{19}$ Fragmentation yields almost exclusively two product ions representing the neutral losses of phosphoric acid $\left[\mathrm{H}_{3} \mathrm{PO}_{4}\right]$ and the PLP moiety $\left[\mathrm{C}_{8} \mathrm{H}_{10} \mathrm{NO}_{5} \mathrm{P}\right]$, respectively. The lack of backbone fragmentation results in MS/MS spectra completely devoid of sequence information discernable by manual interpretation or database search tools. However, we demonstrate that precursor $m / z$ values of MS/ MS spectra exhibiting the signature peaks of PLP-modified peptides can be mapped to in silico peptides for accurately assigning the active-site PLP bonding residue. In addition, we present an enrichment strategy for detecting PLPmodified peptides using LC/MS/MS. These protocols are demonstrated on a known PLP-dependent enzyme; alanine racemase (Bacillus stearothermophilus; $\mathrm{MW}=44 \mathrm{kDa}$ ). ${ }^{20}$

\section{EXPERIMENTAL}

\section{Chemicals}

All materials and chemicals were purchased from SigmaAldrich (St. Louis, MO, USA) unless otherwise stated.

\section{Synthesis and LC/MS/MS analysis of a PLP- modified peptide}

A PLP-modified peptide was synthesized by incubation of the peptide (sequence HHLGGAKQAGDV) in $200 \mu \mathrm{L}$ of $100 \mathrm{mM}$ N-2-hydroxyethylpiperizine-N'-ethanesulfonic acid (HEPES) (pH 7.8) with a saturating amount of PLP and $5 \mu \mathrm{L}$ of $1 \mathrm{M} \mathrm{NaBH}_{4}$ for $1 \mathrm{~h}$ in the dark. The reaction products were then analyzed via LC/MS/MS using a Bioanalyzer LC system from Michrom Bioresources, Inc. (Auburn, CA, USA) with a reversed-phase C18 column $(5 \mu \mathrm{m}, 300 \AA$, $2.0 \times 150 \mathrm{~mm}$; Reliasil, Ontario, CA, USA). An acetonitrile gradient (5-80\%) in $0.1 \%$ trifluoroacetic acid (TFA) was employed at a flow rate of $65 \mu \mathrm{L} / \mathrm{min}$. The LC system was connected in-line to a LCQ Deca ion trap mass spectrometer (ThermoFisher Scientific, Inc., San Jose, CA, USA) operated in data-dependent mode. A total of $3 \times 10^{6}$ ions were targeted per MS scan and $1 \times 10^{6}$ precursor ions were targeted for isolation for MS/MS spectral acquisition. A source voltage of $2.90 \mathrm{kV}$ and capillary temperature of $220^{\circ} \mathrm{C}$ were applied.

\section{$\mathrm{NaBH}_{4}$ reduction of the Schiff base in alanine racemase}

About $300 \mu \mathrm{g}$ of alanine racemase (lyophilized powder containing a substoichiometric amount of PLP) was dis- 
solved in $200 \mu \mathrm{L}$ of $100 \mathrm{mM}$ HEPES (pH 7.8) and $5 \mu \mathrm{L}$ of $1 \mathrm{M}$ $\mathrm{NaBH}_{4}$ (also dissolved in HEPES buffer) was added to reduce the Schiff base. The reduction reaction was allowed to proceed undisturbed for $1 \mathrm{~h}$ in the dark. UV-visible spectra of alanine racemase were acquired (scan range 300-500 nm) using a DU 530 Life Sciences UV/VIS spectrophotometer (Beckman Coulter, Fullerton, CA, USA) before reduction to confirm the presence of PLP linked by a Schiff base and after reduction to confirm the presence of a reduced Schiff base (band at $\sim 325 \mathrm{~nm}$; data not shown). The protein was then dialyzed against $25 \mathrm{mM}$ ammonium bicarbonate ( $\mathrm{pH} 7.8$ ).

\section{Proteolytic digestion and $\mathrm{CNBr}$ cleavage of the enzymes}

Before digestion, disulfide bonds were reduced with $5 \mu \mathrm{L}$ of $200 \mathrm{mM}$ dithiothreitol (DTT) (1 h incubation at room temperature (RT)) and the cysteine residues were alkylated with $20 \mu \mathrm{L}$ of $200 \mathrm{mM}$ iodoacetamide (IAA) (1 h incubation at $\mathrm{RT}$ in the dark). The alkylation reaction was quenched with $20 \mu \mathrm{L}$ of $200 \mathrm{mM}$ DTT ( $1 \mathrm{~h}$ incubation at RT). After drying to an approximate volume of $5 \mu \mathrm{L}$, the enzyme was diluted in $100 \mu \mathrm{L}$ of cyanogen bromide $(\mathrm{CNBr})$ solution $(2 \mathrm{mg} / \mathrm{mL}$ $\mathrm{CNBr}$ in $70 \%$ formic acid pre-purged with $\mathrm{N}_{2}$ gas) and incubated at RT in a fume hood for $2 \mathrm{~h}$ in the dark. The mixture was dried under $\mathrm{N}_{2}$ gas and redissolved in water. $\mathrm{CNBr}$ fragments were separated by HPLC on a reversedphase C4-packed column ( $5 \mu \mathrm{m}, 300 \AA$, $1.0 \times 150 \mathrm{~mm}$; GraceVydac, Deerfield, IL, USA) and fractions corresponding to chromatographic peaks (detected at $214 \mathrm{~nm}$ ) were collected and screened for the presence of a reduced Schiff base (band at $\sim 325 \mathrm{~nm}$; data not shown) using scanning mode UVvisible spectroscopy. The Schiff base-containing fraction was dried and diluted in $25 \mathrm{mM}$ ammonium bicarbonate ( $\mathrm{pH} 7.8$ ) and digested with $4 \mu \mathrm{g}$ of trypsin (Promega, Madison, WI, USA), overnight at $37^{\circ} \mathrm{C}$.

\section{LC/MS/MS and data analysis of digestion products of Schiff base-containing $\mathrm{CNBr}$ fragments}

The resulting tryptic digestion products were analyzed via LC/MS/MS using a reversed-phase C18 column $(5 \mu \mathrm{m}$, $300 \AA$, $2.0 \times 150$ mm; Reliasil, Ontario, CA, USA). The same LC and MS conditions were used as described above. MS/ MS peak lists from the raw files were extracted (.dta format) using BioworksBrowser version 3.3.1 SP1 (ThermoFisher Scientific Inc., San Jose, CA, USA). The .dta files were then converted into .mgf format (as one concatenated file) using a Perl script (merge.pl) available from Matrix Science Inc. (Boston, MA, USA). The .mgf file was then analyzed with the Mascot database searching software from Matrix Science Inc. (Boston, MA, USA) using the complete Swiss-Prot proteome database (release 56.9). ${ }^{21}$ The following fixed settings and modifications were used in the searches: trypsin as the protease; carbamidomethylation (C); and the precursor and product ion mass tolerances were set at $1 \mathrm{Da}$. The variable modifications included deamidation ( $\mathrm{N}$ and $\mathrm{Q}$ ), oxidation (M), homoserine lactone (M), and PLP (K). Lysine incurs a mass increase of 231.030 Da (residue mass $=359.125 \mathrm{Da}$ ) upon reduction of the Schiff base linking it to PLP. ${ }^{14,15}$ Peptide identifications and residue modifications were accepted if their search scores were above the confidence threshold (95\% confidence interval) as established by Mascot.

\section{RESULTS}

\section{CID fragmentation MS/MS spectra of peptides reductively aminated to PLP}

Our initial experimental design for mapping PLP modifications in proteins included reduction of the Schiff base with $\mathrm{NaBH}_{4}$, digestion of the protein with trypsin, LC/MS/MS analysis, and data processing with Mascot. This approach failed to yield any evidence of a peptide carrying a PLP modification. Since a phosphate group is part of the PLP moiety, it was hypothesized that perhaps poor backbone fragmentation 9,10 and/or reduced detection efficiency (perhaps due to ion suppression or low stoichiometry) of the precursor ion of the modified peptide may have contributed to the undetected modification ${ }^{18}$ as these are common characteristics of phosphopeptides when analyzed by MS.

This prompted us to synthesize a PLP-modified peptide as a model to test our hypotheses and analyzed it by CID. The MS/MS spectra for this peptide (sequence HHLGGAKQAGDV) as $+1,+2$, and +3 charged precursor ions are displayed in Figs. 1(A), 1(B), and 1(C), respectively. The spectra suggest that fragmentation is primarily limited to the losses of $\left[\mathrm{H}_{3} \mathrm{PO}_{4}\right](-98 \mathrm{Da})$ and $\left[\mathrm{C}_{8} \mathrm{H}_{10} \mathrm{NO}_{5} \mathrm{P}\right](-231 \mathrm{Da})$, referred to here as the PLP moiety (inset Fig. 1), from the precursor ion, respectively. In most cases these are neutral losses, $\left[\left(\mathrm{MH}_{\mathrm{n}}\right)^{\mathrm{n}+}-\mathrm{H}_{3} \mathrm{PO}_{4}\right]^{\mathrm{n}+}$ and $\left[\left(\mathrm{MH}_{\mathrm{n}}\right)^{\mathrm{n}+}-\left(\mathrm{C}_{8} \mathrm{H}_{10} \mathrm{NO}_{5} \mathrm{P}\right)\right]^{\mathrm{n}+}$, although in Fig. 1(C) the loss of the PLP moiety was accompanied by the loss of an additional mass unit and one charge unit $\left[\left(\mathrm{MH}_{3}\right)^{3+}-\left(\mathrm{C}_{8} \mathrm{H}_{11} \mathrm{NO}_{5} \mathrm{P}\right)^{+}\right]^{2+}$. The precursor ion MS scans (data not shown) showed that the products from the reduction reaction included a mixture of unmodified peptide with a proportion of peptide carrying a single PLP modification. For the population of ions carrying a single PLP modification, we cannot be sure if the modification occurred primarily on the side-chain lysine amino group, on the $\mathrm{N}$ terminus, or in a mixture of the two sites using this analytical approach. However, this experiment provided some insight into the effect that a reductively aminated PLP modification has on the fragmentation of peptides with CID. For comparison, MS/MS spectra of the underivatized peptide are displayed in Fig. 2. Contrary to the PLP-modified analog, the underivatized peptide exhibits significant backbone fragmentation. A scarcity of sequence ion peaks could represent one explanation why a PLP modification from the alanine racemase digestion mixture went undetected by Mascot. However, manual screening of the dataset found no MS/MS spectra exhibiting these characteristics.

\section{Enrichment of the PLP-modified CNBr- generated fragment of alanine racemase}

It was then considered that reduced detection efficiency was a second contributing factor to detecting the elusive modification based analogously to phosphopeptides which exhibit ion suppression and lower stoichiometry relative to nonphosphorylated peptides. ${ }^{18,23}$ Therefore, an enrichment scheme for PLP-modified peptides was then applied to reduce the complexity of the peptide mixture resulting from 


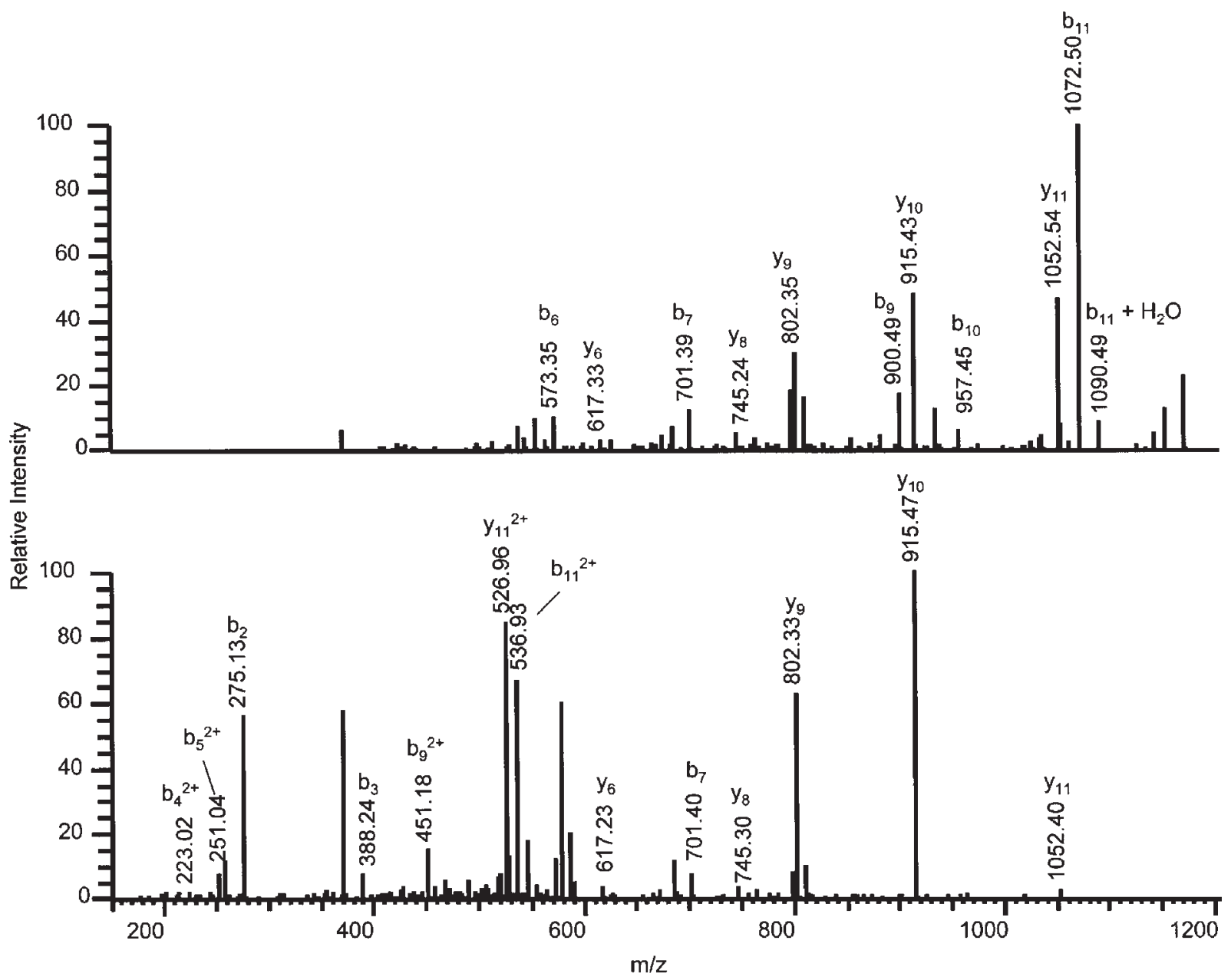

Figure 2. ESI-MS/MS spectra of (A) singly and (B) doubly charged precursor ions of the underivatized standard peptide with the amino acid sequence HHLGGAKQAGDV.

the tryptic digestion of the protein. The general scheme included the following steps subsequent to $\mathrm{NaBH}_{4}$ reduction of the Schiff base, reduction of disulfide bonds, and alkylation of cysteine residues: (1) The protein was treated with $\mathrm{CNBr}$ which chemically cleaves the amide backbone on the C-terminal side of methionine residues converting them into a homoserine lactone. ${ }^{22}$ Since methionine occurs at a low frequency in most proteins, this typically generates fairly large peptide fragments. (2) The $\mathrm{CNBr}$ fragments were separated by HPLC and fractions corresponding to chromatographic peaks (detected at $214 \mathrm{~nm}$ ) were collected. (3) The fractions were then screened using UV-visible spectroscopy for the characteristic band $(325 \mathrm{~nm})$ of a PLP modification with a reduced Schiff base. ${ }^{14,15}$ Figure 3 displays a HPLC chromatogram of the separated $\mathrm{CNBr}$ fragments of alanine racemase. The inset shows a UV-visible spectrum of the fraction corresponding to the chromatographic peak marked with an asterisk in the chromatogram. The distinctive band at $325 \mathrm{~nm}$ was only observed in this fraction implying the PLP modification resided within that fragment of the protein.

\section{Identification of the PLP-modified CNBr fragment}

The HPLC fraction containing the PLP-modified CNBr fragment was digested with trypsin and two aliquots of the resulting peptide mixture were analyzed via LC/MS/MS.
While it was considered to try and analyze the CNBrgenerated products directly, we decided to proteolyze further with trypsin considering that $\mathrm{CNBr}$ fragments are typically too large to yield informative MS/MS spectra. The data were processed with Mascot using a PLP modification (with a reduced Schiff base linkage) as a variable modification on lysine among the other search parameters. Table 1 lists the peptides identified by Mascot. With the exception of peptide \#1 in the table, all peptides detected reside in the theoretical $\mathrm{CNBr}$ fragment A36-M130 suggesting that the PLP modification resides within that fragment. There are three lysine residues within that fragment of the protein (K39, K76, and K129) representing possible sites of PLP modification. However, there were no PLP-modified peptides identified when the data was analyzed by Mascot. Only unmodified K129 was detected within the fragment. It is assumed that unmodified $\mathrm{K} 39$ and $\mathrm{K} 76$ would not be detected since cleavage at these sites would result in peptides too small to be analyzed by the instrumentation used. Coverage at these sites would more likely be observed if there was a missed tryptic cleavage event or a PLP modification since lysine residues aminated by PLP resist cleavage by trypsin. ${ }^{14,15}$ Furthermore, detection of any unmodified lysine residue could not be ruled out as the PLP-bonding site since the content of PLP was sub-stoichiometric relative to the protein (according to the distributor). Nonetheless, this experiment narrowed 


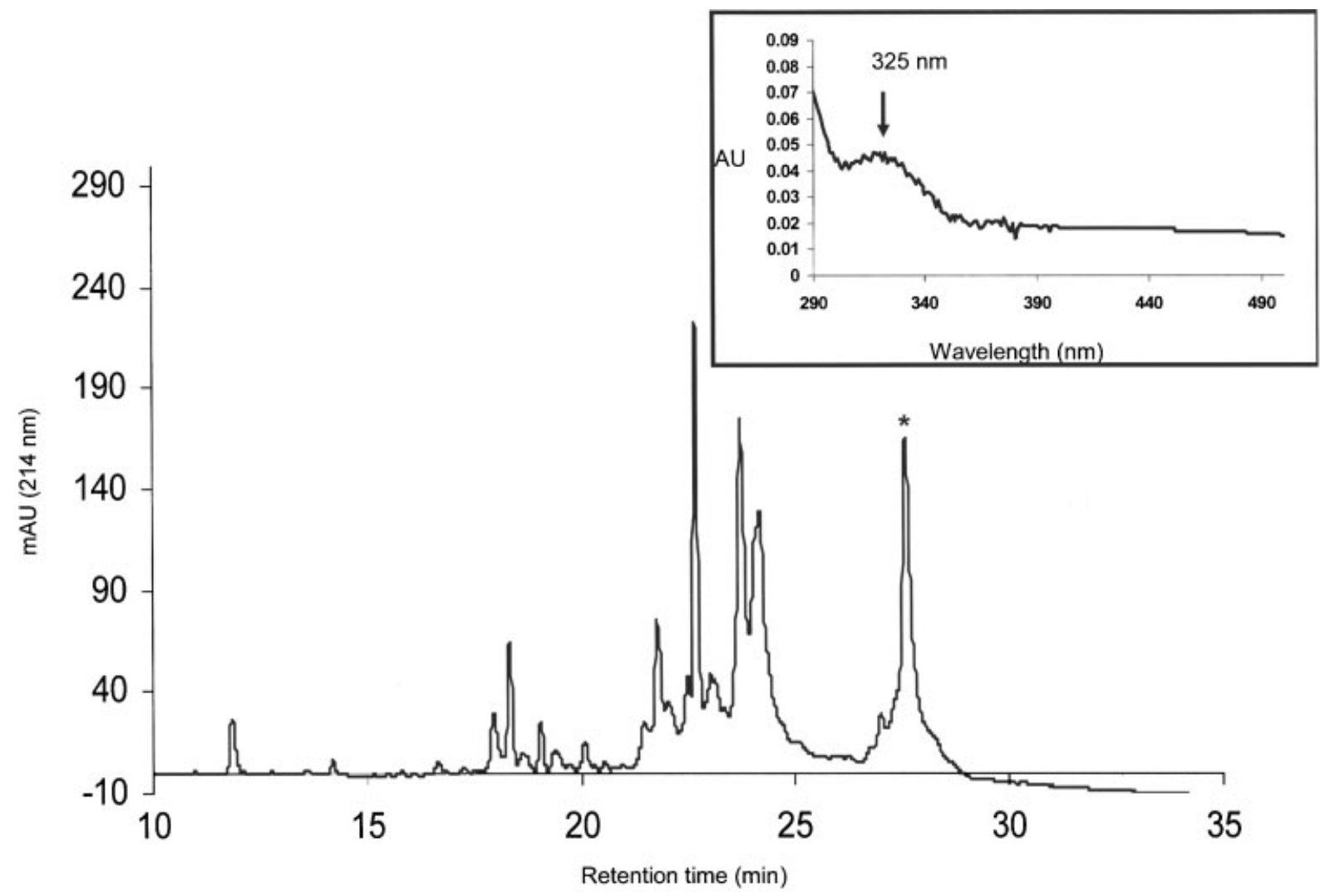

Figure 3. HPLC chromatogram of CNBr-generated fragments of alanine racemase. The Schiff base-linked PLP modification was previously reduced with $\mathrm{NaBH}_{4}$. The chromatographic peak marked with an asterisk represents the single fraction exhibiting a UV-visible spectrum (inset) with a band at $325 \mathrm{~nm}$ characteristic of a reduced Schiff base linkage of PLP to a lysine residue.

the PLP-bonding site possibilities from thirteen total lysine residues in the protein to just three.

\section{Identification of the PLP modification site with neutral loss scanning combined with peptide mass fingerprinting}

PLP modification sites were assigned by using the software Excalibur (ThermoFisher Scientific Inc., San Jose, CA, USA) for neutral-loss screening for MS/MS spectra exhibiting distinctive product ion peaks diagnostic for PLP-modified peptides followed by manual peptide mass fingerprinting. With K39, K76, and K129 representing the candidate PLPbonding sites in alanine racemase, we scanned the MS/MS spectra in the dataset for those that exhibited the characteristic neutral loss peaks, $\left[\left(\mathrm{MH}_{\mathrm{n}}\right)^{\mathrm{n}+}-\mathrm{H}_{3} \mathrm{PO}_{4}\right]^{\mathrm{n}+}$ and $\left[\left(\mathrm{MH}_{\mathrm{n}}\right)^{\mathrm{n}+}-\right.$ $\left.\mathrm{C}_{8} \mathrm{H}_{10} \mathrm{NO}_{5} \mathrm{P}\right]^{\mathrm{n}+}$, that were observed when the model peptide was analyzed (Fig. 1). Since the model peptide exhibited loss of both $\left[\mathrm{H}_{3} \mathrm{PO}_{4}\right]$ and the PLP moiety, MS/MS scans displaying peaks for both neutral losses were examined. As displayed in Fig. 4, the MS/MS spectra were screened for both neutral loss products characteristic to PLP-modified peptides. Figure 4(A) displays the precursor ion base-peak chromatogram and Fig. 4(B) displays a chromatogram plotting the intensities of any product ions in the MS/MS spectra (annotated by their scan numbers) corresponding to a neutral loss of $\left[\mathrm{H}_{3} \mathrm{PO}_{4}\right]$ from the precursor ion $\mathrm{m} / \mathrm{z}$ value. In this case, triply charged precursor ions were considered

Table 1. Peptides identified from the CNBr fragment A36-M130 of alanine racemase*

\begin{tabular}{llcc}
\hline Peptide \# & Peptide sequence & Residue \#s & Run \# \\
\hline 1 & MNDFHR & 1 to 6 & 1 \\
2 & ANAYGHGDVQVAR & 40 to 52 & 53 to 61 \\
3 & TALEAGASR & 62 to 74 & 2 \\
4 & LAVAFLDEALALR & 77 to 100 & 1,2 \\
5 & GIEAPILVLGASRPADAALAAQQR & 101 to 107 & 2 \\
6 & IALTVFR & 108 to 129 & 1 \\
7 & SDWLEEASALYSGPFPIHFHLK & 2 & 1 \\
\hline
\end{tabular}

* The HPLC fraction containing this fragment exhibited a UV-visible spectrum characteristic of a reduced Schiff base linkage between PLP and the enzyme. 

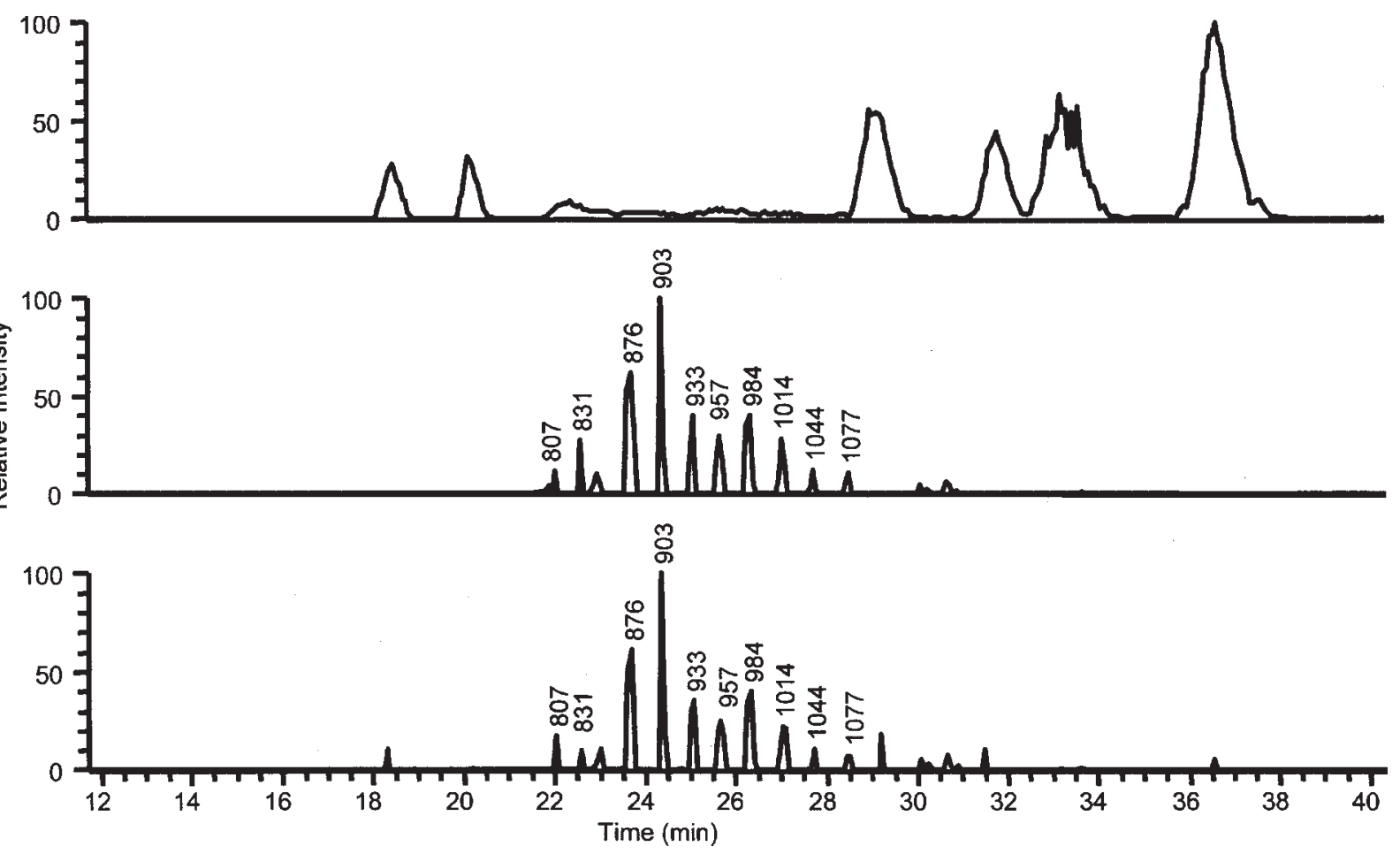

Figure 4. The base-peak precursor ion chromatogram from the LC/MS/MS analysis of the tryptic products of the $\mathrm{CNBr}$ fragment $\mathrm{A} 36-\mathrm{M} 130$ of alanine racemase $(\mathrm{A})$ along with the corresponding plots of characteristic neutral losses of $\mathrm{H}_{3} \mathrm{PO}_{4}$ (B) and the PLP moiety (C) product ion signals respectively from triply charged precursor ions. The plots were constructed by scanning for losses of 32.7 (B) and $77 \mathrm{~m} / \mathrm{z}$ units (C), respectively.

which would incur a loss of $\sim 32.7 \mathrm{~m} / \mathrm{z}$ units $(-98 \mathrm{Da}$ ) upon the loss of $\left[\mathrm{H}_{3} \mathrm{PO}_{4}\right]$. Figure $4(\mathrm{C})$ displays the corresponding chromatogram for the neutral loss of the PLP moiety which would incur a loss of $77 \mathrm{~m} / \mathrm{z}$ units $(-231 \mathrm{Da})$ from the precursor ion. The data was also screened in this fashion for the neutral loss peaks from doubly charged precursor ions (data not shown). Since both neutral loss products are characteristic of PLP-modified peptides, scans that produced product ion signals for both (such as scan 903 in Figs. 4(B) and $4(\mathrm{C})$ ) were analyzed manually. Figures 5(A) and 5(B) display representative MS/MS spectra from a doubly and triply charged precursor ion $(\mathrm{m} / \mathrm{z}$ values 993.75 and 663.00, respectively) which exhibit these spectral features along with a scarcity of peaks representing evidence of other fragmentation events. The lack of sequence ion peaks explains why neither of these spectra could be matched to a peptide by Mascot. Table 2 lists theoretical tryptic products from the $\mathrm{CNBr}$ fragment A36-M130 that represent possible PLPmodified peptides. The precursor $\mathrm{m} / \mathrm{z}$ values 993.75 and
663.00 representing the spectra in Fig. 5 most closely match the theoretical mass of the fragment 36-52, AVVK'ANAYGHGDVQVAR, in its +2 and +3 charge states, respectively, including the mass of the PLP moiety on the modified lysine residue $\left(\mathrm{K}^{\prime}\right)$. Despite exhibiting lower mass accuracy compared to current instrumentation, the LCQ ion trap is adequate for this application considering that the sample consists of a simplified peptide mixture generated from the enrichment of a fragment of a single purified protein of known sequence. Since the peptide has one lysine residue, K39, the PLP-bonding site can be unambiguously assigned to this residue. This agrees with the known PLP-bonding site in alanine racemase. ${ }^{20}$ It is noteworthy that PLP-modified peptides exhibited poor chromatographic resolution compared to unmodified peptides as evident by the broadness of the elution profiles displayed in Figs. 4(B) and 4(C). This could also represent a contributing factor to the difficulty in detecting them in complex peptide mixtures.

Table 2. Possible theoretical PLP-modified peptides from fragment A36-M130

\begin{tabular}{llcrr}
\hline & & & \multicolumn{2}{c}{ Theoretical $m / z$ values } \\
\cline { 3 - 5 } Lysine residue & Peptide sequence & Residue \#s & $\left(\mathrm{MH}_{2}\right)^{2+}$ & $\left(\mathrm{MH}_{3}\right)^{3+}$ \\
\hline K39 & AVVK'ANAYGHGDVQVAR & 36 to 52 & 993.48 & 662.66 \\
K76 & EK'GIEAPILVLGASRPADAALAAQQR & 75 to 100 & 1438.76 & 959.51 \\
K129 & SDWLEEASALYSGPFPIHFHLK'h & 108 to 130 & 1429.66 & 953.45
\end{tabular}

${ }^{*} \mathrm{~K}^{\prime}$ represents a reductively aminated PLP modification on lysine. Homoserine lactone is represented by $\mathrm{h}$. 


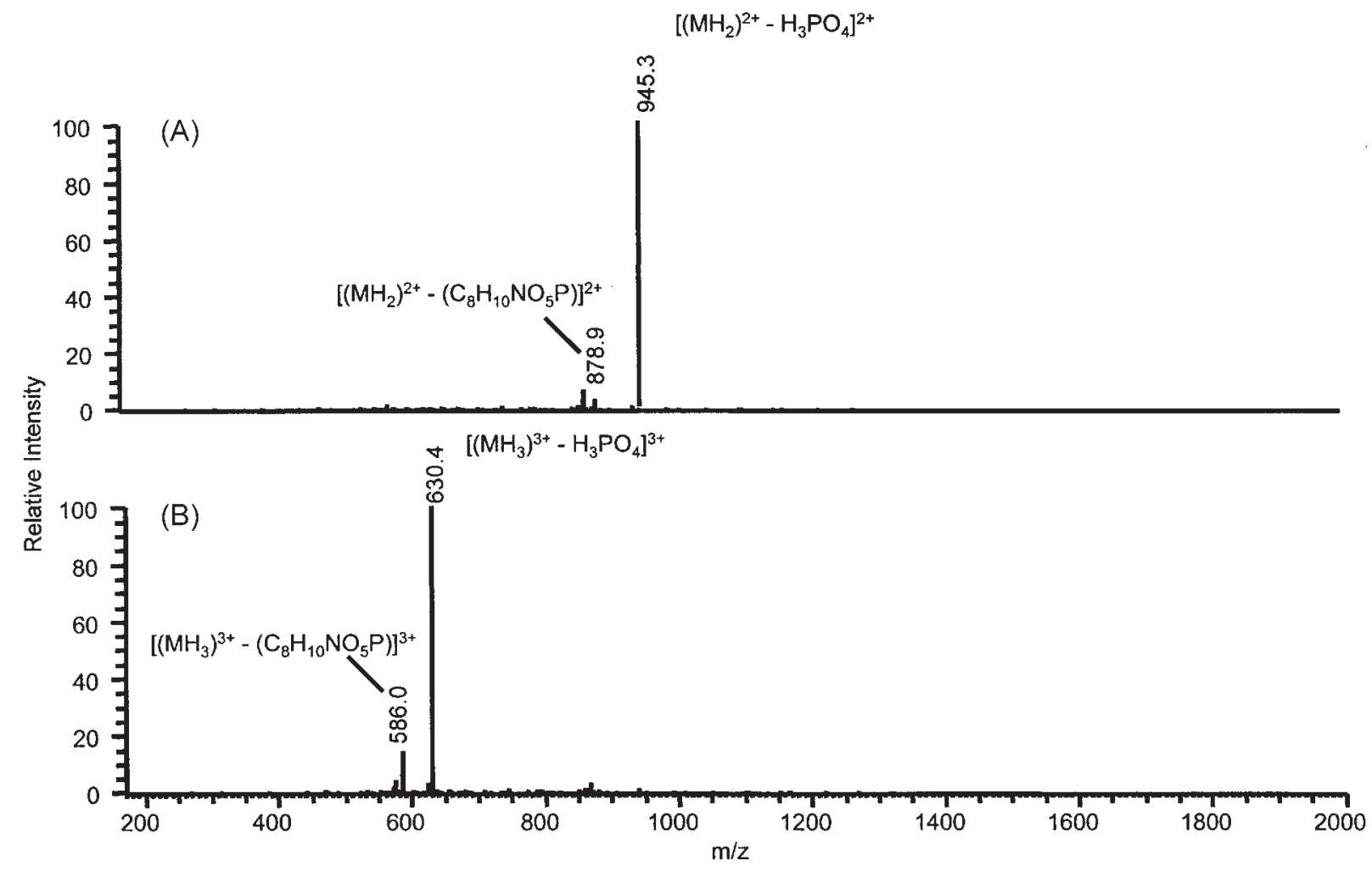

Figure 5. ESI-MS/MS spectra of the PLP-modified tryptic peptide 36-52, AVVK'ANAYGHGDVQVAR, of alanine racemase. The MS/MS spectra represent the doubly charged precursor ion, $m / z 993.75$ (A), and the triply charged precursor ion, $m / z 663.00$ (B).

\section{DISCUSSION}

Peptides modified by PLP (reductively linked to a lysine side chain) exhibit mass spectral characteristics similar to those observed for phosphopeptides including impaired backbone fragmentation. Distinctive to PLP-modified peptides is the neutral loss product corresponding to the PLP moiety itself in addition to the loss of $\mathrm{H}_{3} \mathrm{PO}_{4}$. Like phosphopeptides, the lack of backbone fragmentation with CID results in MS/ MS spectra that provide little sequence information. We demonstrated an enrichment procedure that enhances detection of PLP-modified peptides by first cleaving the protein with $\mathrm{CNBr}$, separating the fragments, and then digesting the fraction exhibiting a characteristic UV-visible spectrum of a reduced Schiff base linkage of PLP to lysine. This results in a much simpler peptide mixture relative to digesting the intact protein with trypsin and reduces the number of candidate lysine residues that may represent the PLP-bonding site. Although processing of the data with Mascot did not yield a peptide hit with a PLP modification, the peptides identified showed that the modification was sequestered within the fragment A36-M130 of the protein. We then demonstrated the mapping of the PLP-bonding site by employing neutral loss screening of all MS/MS spectra combined with peptide mass fingerprinting. Our results provide foresight to future investigators who can now anticipate the mass spectral characteristics and limitations when attempting to locate PLP modification sites in proteins using CID tandem mass spectrometry. In future studies, alternative enrichment strategies may be applied such as immobilized metal-affinity chromatography ${ }^{23}$ or metal oxides $^{24}$ that have been effective in phosphorylation site mapping. Alternative fragmentation techniques to CID, such as electron transfer dissociation, ${ }^{25}$ electron capture dissociation ${ }^{26}$ or neutral-loss triggered $\mathrm{MS}^{3}$ acquisition, ${ }^{27}$ have been effective for analyzing peptides with labile modifications and may also be applicable to PLP modifications.

\section{Acknowledgements}

Portions of this work were done while both authors were at Michigan State University. We acknowledge MSU and the MSU Mass Spectrometry Facility for assistance and partial support of this work.

\section{REFERENCES}

1. Denessiouk KA, Denesyuk AI, Lehtonen JV, Korpela T, Johnson MS. Proteins: Struct. Funct. Genet. 1999; 35: 250.

2. Toney MD. Arch. Biochem. Biophys. 2005; 433: 279.

3. Liu JQ, Dairi T, Kataoka M, Shimizu S, Yamada H. J. Bacteriol. 1997; 179: 3555.

4. Cho SW, Yoon HY, Ahn JY, Lee EY, Lee J. Eur. J. Biochem. 2001; 268: 3205.

5. Witze ES, Old WM, Resing KS, Ahn NG. Nat. Methods 2007; 10: 798 .

6. Perkins DN, Pappin DJC, Creasy DM, Cottrell JS. Electrophoresis 1999; 20: 3551.

7. Zhu H, Bilgin M, Snyder M. Annu. Rev. Biochem. 2003; 72: 783.

8. Link AJ, Eng J, Schieltz DM, Carmack E, Mize GJ, Morris DR, Garvik BM, Yates JR III. Nat. Biotechnol. 1999; 17: 676.

9. DeGnore JP, Qin J. J. Am. Soc. Mass Spectrom. 1998; 9: 1175.

10. Tholey A, Reed J, Lehmann WD. J. Mass Spectrom. 1999; 34: 117.

11. John RA. Biochim. Biophys. Acta 1995; 1248: 81. 
12. Nishigori H, Toft D. J. Biol. Chem. 1979; 254: 9155.

13. Bürger E, Görish H. Eur. J. Biochem. 1981; 118: 125.

14. Chen D, Frey PA. Biochemistry 2001; 40: 596.

15. Tang K, Harms A, Frey PA. Biochemistry 2002; 41: 8767.

16. Woon KP, Paik DC, Kim S. Trends Biochem. Sci. 2007; 32: 146.

17. Ubersax JA, Ferrell JE. Nat. Rev. Mol. Cell Biol. 2007; 8: 530.

18. Asara JM, Allison J. J. Am. Soc. Mass Spectrom. 1999; 10: 35.

19. Pappin DJ, Hojrup P, Bleasby AJ. Curr. Biol. 1993; 3: 327.

20. Watababe A, Kurokawa Y, Yoshimura T, Kurihara T, Soda K, Esaki N. J. Biol. Chem. 1999; 274: 4189.

21. Gasteiger E, Gattiker A, Hoogland C, Ivanyi I, Appel RD, Bairoch A. Nucleic Acids Res. 2003; 31: 3784.
22. Simpson RJ. Proteins and Proteomics. Cold Spring Harbor Press: New York, 2003.

23. Ficarro SB, McCleland ML, Stukenberg PT, Burke DJ, Ross MM, Shabanowitz J, Hunt DF, White FM. Nat. Biotechnol. 2002; 20: 301.

24. Simon ES, Young M, Chan A, Bao Z, Andrews PC. Anal. Biochem. 2008; 377: 234

25. Coon J, Syka J, Schroeder M, Shabanowitz J, Hunt D. Proc. Natl. Acad. Sci. USA 2004; 101: 9528.

26. Shi SDH, Hemling ME, Carr SA. Anal. Chem. 2001; 73: 19.

27. Beausoleil SA, Jedrychowski M, Schwartz D, Elias JE, Villén J, Li J, Cohn MA, Cantley LC, Gygi SP. Proc. Natl. Acad. Sci. USA 2004; 101: 12130. 